\title{
Composição Corporal e Exigências Energéticas e Protéicas de Bovinos Mestiços Leiteiros e Zebu, Castrados, em Regime de Recria e Engorda ${ }^{1}$
}

\section{Alfredo Acosta Backes², Mário Fonseca Paulino ${ }^{3}$, Dorismar David Alves ${ }^{4}$, Luciana Navajas Rennó ${ }^{5}$, Sebastião de Campos Valadares Filho ${ }^{3}$, Rogério de Paula Lana ${ }^{3}$}

\begin{abstract}
RESUMO - Para determinar as exigências energéticas e protéicas de animais mestiços leiteiros e zebu, castrados, nas fases de recria e engorda, foram utilizados 47 bovinos machos castrados, com peso vivo médio de $266 \mathrm{~kg}$, sendo 16 zebu e 31 mestiços leiteiros (16 1/2 sangue Holandês x Gir e 15 1/2 sangue Holandês x Guzerá). Doze animais (quatro de cada grupo racial) serviram de referência, 11 foram alimentados para mantença e os 24 restantes foram distribuídos em dois tratamentos (zebu e mestiços leiteiros), em duas fases (recria e engorda). O peso inicial dos animais foi de 257 e $276 \mathrm{~kg}$, com avaliação até os 340 e $480 \mathrm{~kg}$, nas fases de recria e de engorda, respectivamente. O volumoso utilizado foi o feno de capim-tifton (Cynodon dactylon). Os conteúdos de gordura, proteína e energia retidos no corpo dos animais foram estimados por meio de equações de regressão do logaritmo do conteúdo corporal de proteína, de gordura ou de energia, em função do logaritmo do PCVZ. As exigências energéticas de mantença (ELm) foram estimadas pelo anti-log do intercepto da regressão linear entre o logaritmo da produção de calor (PC) e o consumo de energia metabolizável (CEM). As exigências de energia líquida dos animais zebu, em fase de recria, foram, em valores absolutos, mais elevadas que as do grupo mestiços leiteiros, porém, na fase de engorda, essa relação foi inversa. A ELm estimada para mestiços e zebu foi de 76,99 e 79,40 kcal/kg 0,75/dia, respectivamente. As exigências de proteína metabolizável e de proteína líquida foram semelhantes entre mestiços e zebu.
\end{abstract}

Palavras-chave: energia, mestiços, proteína, zebu

\section{Body Composition and Energy and Protein Requirements of Dairy Crossbreeds and Zebu Bovines, Castrated, in the Growing and Fattening Phases}

\begin{abstract}
Forty-seven bovines (average live weight of $266 \mathrm{~kg}$ ), 16 zebu and 31 dairy crossbreeds ( 16 crossbreed Holstein x Gir and 15 Holstein x Guzera), were used to evaluate energy and protein requirements. Twelve animals (four of each racial group) were used as reference bovines, eleven were fed for maintenance and the 24 remaining were allotted to two treatments (zebu and dairy crossbreeds) in two phases (growing and fattening). Growing phase started when bovines reached $257 \mathrm{~kg}$ and lasted up to $340 \mathrm{~kg}$ of live weight, and fattening phase with initial live weight of $276 \mathrm{~kg}$ and lasted up to $480 \mathrm{~kg}$. Tifton (Cynodon dactylon) grass hay was used as feedstuff. Protein, fat and energy contents retained in body were estimated by regression equation of the logarithm of protein, fat or energy body content, as a function of the logarithm of empty weight (EBW). Net energy requirements for maintenance (NEm) were estimated as the intercept anti-log of the equation obtained by linear regression among the logarithm of heat production (HP) and the metabolizable energy intake (MEI). Net energy requirements of zebu animals, in growing phase, was greater than dairy crossbreeds group, however in fattening phase that relationship was inverse. Net energy requirements for maintenance estimated for dairy crossbreeds and zebu were 76.99 and $79.40 \mathrm{kcal} / \mathrm{EBW}{ }^{75}$, respectively. Metabolizable protein and net protein requirements were similar between dairy crossbreed and zebu.
\end{abstract}

Key Words: crossbreeds, energy, protein, zebu

\section{Introdução}

A composição corporal - importante aspecto para determinação das exigências nutricionais de mantença e produção de bovinos - pode ser afetada por diferentes fatores (sexo, raça, peso, taxa de ganho de peso, genética, manejo nutricional, entre outros).
Entre os diferentes tecidos corporais, o tecido adiposo é o último a se desenvolver, e, entre os vários locais de deposição, a gordura intramuscular (marmoreio) também desenvolve-se por último.

A concentração de gordura no ganho de peso tende a elevar-se, à medida que os animais ficam mais pesados, o que acarreta aumento nas exigências líquidas de energia para ganho de peso, à medida que

\footnotetext{
1 Parte da tese de Doutorado do primeiro autor

2 Pesquisador e professor PRODOC da UFS, Zootecnista, Dr. Av. São João Batista, 638, Cond. Resid. Vila Rica, BI Barbacena, ap303,

Bairro Castelo Branco - Aracaju, SE, CEP: 49097-000. E.mail: abackes@ufs.com.br

3 Professor do Departamento de Zootecnia/UFV.

4 Zootecnista, Msc. Estudante de Doutorado/UFV.

5 Professora da UNIPAC, Juiz de Fora.
} 
aumentam o peso vivo e a taxa de ganho de peso. Freitas (1995) observou que as exigências líquidas de energia em Mcal por kg de ganho de peso corporal vazio foram maiores, à proporção que se elevava o peso do corpo vazio, em virtude do aumento na deposição de gordura e da redução no teor de proteína, com a elevação do peso do animal.

Com o incremento do peso vivo do animal, geralmente acima de um ano de idade, ocorrem decréscimo na proporção de proteína e aumento na proporção de gordura no peso de corpo vazio, em razão da redução do crescimento muscular e do aumento do desenvolvimento do tecido adiposo. Como conseqüência, a exigência de energia aumenta e a exigência de proteína decresce, concomitantemente. Segundo Paulino et al. (1999), o valor energético dos ganhos de peso vivo depende da proporção de gordura e de proteína depositados nos tecidos. Como essas proporções mudam conforme o aumento no peso vivo e estádio de maturidade, os valores de energia do tecido também mudam. O verdadeiro determinante da composição dos ganhos não é o peso corporal absoluto, mas o peso relativo ao peso à maturidade do animal - teoria sustentada pelos efeitos do sexo sobre a composição dos ganhos (Veloso et al., 2002). As fêmeas são menores que os machos à maturidade e, com o mesmo peso, ganham mais gordura e energia, sendo que os animais castrados são intermediários entre os machos inteiros e as fêmeas.

Ao comparar a composição corporal de animais zebuínos e mestiços, Fontes (1995) observou que animais zebuínos, sobretudo animais castrados, depositam gordura precocemente. Maiores teores de gordura corporal de zebuínos em relação a mestiços leiteiros foram encontrados por Teixeira et al. (1987), em decorrência da seleção natural, que leva alguns ruminantes a armazenarem, nos períodos de abundância e de melhor qualidade dos pastos, reserva corporal para manutenção nas épocas de escassez alimentar, apresentando maior probabilidade de sobrevivência que animais menos adaptados (Holechek et al., 1989, citados por Paulino et al., 1999).

As exigências de proteína dos ruminantes são atendidas pelos aminoácidos absorvidos no intestino delgado, oriundos, principalmente, da proteína microbiana e da proteína dietética não-degradada no rúmen (Paulino et al., 1999). Segundo esses autores, as exigências líquidas de proteína para bovinos nas fases de crescimento e engorda são função do conteúdo de matéria seca desengordurada do peso ganho, do peso vivo, do nível de ganho de peso, do grupo genético e do sexo, sendo menores para novilhos que para machos não-castrados e para animais de raça de maturidade precoce que de raças de maturidade tardia. Ao analisarem a concentração de proteína corporal, Backes et al. (2002) observaram que, com o aumento do peso vivo, a concentração de proteína no corpo vazio diminui e, conseqüentemente, as exigências de proteína para ganho de peso reduzem com o aumento do peso vivo e da taxa de ganho de peso, concordando com os diferentes sistemas de alimentação (NRC, 1984; AFRC, 1993; NRC, 1996).

As exigências de energia para mantença dos animais podem ser definidas como a quantidade de energia dos alimentos consumidos que não resultaria em ganhos ou perdas de energia corporal (NRC, 1984, 1996) e, também, como a quantidade de energia equivalente a quantidade de calor produzido pelo animal em estado de jejum. A produção de calor de jejum é estimada por regressão, sendo extrapolada para o nível zero de ingestão de energia metabolizável. A energia de mantença é um atributo importante, pois, segundo Ferrel \& Jenkins (1985), 65 a 70\% da energia necessária para produção de carne é utilizada para suprir o requerimento de mantença.

A energia líquida foi dividida por Lofgreen \& Garrett (1968) em energia líquida de mantença (ELm) e energia líquida para ganho de peso (ELg), com valor de mantença em 77 kcal/PV ${ }^{0,75}$. Porém, conforme NRC (1984), esse valor refere-se a animais estabulados, sem estresse e com atividade mínima, além de ter sido obtido somente com taurinos. Em animais em crescimento, segundo NRC (1996), as raças zebuínas requerem cerca de $10 \%$ menos energia que as taurinas para mantença, enquanto as raças mestiças têm exigências intermediárias. Pires et al. (1993) observaram que os animais Nelore obtiveram menor valor de exigência de energia (20\%) para mantença em relação aos mestiços. Segundo esses autores, a menor exigência de mantença dos animais Nelore indica a utilização mais eficaz da energia metabolizável para mantença em relação aos mestiços ou, também, a menor atividade metabólica desses animais. Ainda, a maior exigência de energia de mantença para os mestiços se deve ao maior conteúdo de proteína corporal, resultando em maior reciclagem de proteína. Fatores como atividade metabólica dos órgãos internos,

\section{R. Bras. Zootec., v.34, n.1, p.257-267, 2005}


local de deposição e distribuição de gordura corporal podem também ter contribuído para as diferenças na exigência de energia líquida de mantença entre os grupos genéticos.

Com relação à exigência líquida de proteína para mantença, parece não existir uma metodologia padrão entre os diferentes sistemas nutricionais para sua determinação. Conforme Véras et al. (2000), as exigências de proteína para mantença de um animal em determinado peso vivo diferem substancialmente entre os sistemas correntes de exigências nutricionais. Essa diferença alcança $100 \%$ a mais que os resultados obtidos pelo NRC $(1984,1989)$ e pelo CNCPS, em comparação ao ARC (1984) e AFRC (1993). Isso ocorre em virtude desses sistemas utilizarem conceitos, fatores e metodologias diferentes para a predição desses requerimentos. O sistema INRA (1988), adotando estudos de balanço de nitrogênio que incluíram perdas por descamações, perdas metabólica fecal e urinária, determinou exigência de mantença de $3,25 \mathrm{~g}$ $\mathrm{PM} / \mathrm{kg}^{0,75}$. Todavia, o NRC (1996) adotou o valor de $3,8 \mathrm{~g} \mathrm{PM} / \mathrm{kg} \mathrm{PV}^{0,75}$, ao passo que o AFRC (1993), de 2,3 $\mathrm{g} \mathrm{PM} / \mathrm{kg} \mathrm{PV}^{0,75}$.

Neste trabalho, foram determinadas as exigências de energia e de proteína de animais mestiços leiteiros e zebu, castrados, nas fases de recria e engorda.

\section{Material e Métodos}

O experimento foi conduzido nas dependências do laboratório de Nutrição Animal do Departamento de Zootecnia da Universidade Federal de Viçosa, em Viçosa (MG). Foram utilizados 47 bovinos machos castrados, com idade média de 11 meses e peso médio de 266kg, sendo 16 zebu e 31 animais mestiços leiteiros ( $16^{1 / 2}$ sangue Holandês x Gir e 15 1 12 sangue Holandês x Guzerá). Doze animais-referência (quatro de cada grupo racial) foram abatidos após o período de adaptação e onze (quatro zebu, quatro Holandês x Gir e três Holandês x Guzerá) receberam dieta com 14\% de PB e relação volumoso:concentrado de 60:40, em consumo restrito de 1,4\% do peso vivo, para atender às exigências de mantença, sendo abatidos 90 dias após o início da fase experimental. Os 24 animais restantes foram pesados e distribuídos em dois tratamentos (zebu e mestiços leiteiros), em dois estádios de crescimento (recria e engorda), em delineamento inteiramente casualizado com oito repetições para mestiços (quatro Holandês x Gir e quatro Holandês x Guzerá) e quatro repetições para zebu. O peso inicial dos animais foi de 257 e $276 \mathrm{~kg}$, com avaliação até os 340 e $480 \mathrm{~kg}$, nas fases de recria e de engorda, respectivamente. $\mathrm{O}$ volumoso foi o feno de capim-Tifton 85 (Cynodon dactylon), fornecido aos animais na forma triturada. As rações, formuladas com base no NRC (1996), foram fornecidas uma vez ao dia e ajustadas de forma que sempre houvesse sobra de $10 \%$ do ofertado. A água foi fornecida permanentemente aos animais (mantidos em baias individuais). A composição química do volumoso e concentrado encontra-se na Tabela 1 e a composição bromatológica das rações, na Tabela 2. Os animais foram pesados a cada 28 dias, após 16 horas, em média, de jejum de sólidos. Antes do abate, os animais também passaram pelo mesmo período médio de jejum de sólidos. Por ocasião do abate, foram coletadas amostras de rúmen-retículo, omaso, abomaso e intestinos após o seu esvaziamento e limpeza, obtendo-se ainda os pesos e amostras de sangue, couro, pés, cabeça e demais órgãos.

As amostras de sangue foram coletadas logo após o abate, acondicionadas em recipientes de vidro e levadas à estufa de ventilação forçada, por 72 horas, para determinação da matéria seca (MS). Após, foram processadas em moinho de bola, ao acondicionamento em recipientes de vidro e às pos-

Tabela 1- Teores médios de matéria seca (MS), matéria orgânica (MO), proteína bruta (PB), extrato etéreo (EE), fibra em detergente neutro (FDN), carboidratos não-fibrosos (CNF) e energia metabolizável (EM) do concentrado e do feno

Table 1 - Dry matter (DM), organic matter (OM), crude protein $(C P)$, ether extract $(E E)$, neutral detergent fiber (NDF), nonfiber carbohydrates (NFC) and metabolizable energy contents of the concentrate and hay

\begin{tabular}{|c|c|c|c|c|}
\hline \multirow{3}{*}{$\begin{array}{l}\text { Itens } \\
\text { Items }\end{array}$} & \multicolumn{4}{|c|}{$\begin{array}{l}\text { Fases } \\
\text { Phases }\end{array}$} \\
\hline & \multicolumn{2}{|c|}{$\begin{array}{c}\text { Recria } \\
\text { Growing }\end{array}$} & \multicolumn{2}{|c|}{$\begin{array}{l}\text { Engorda } \\
\text { Fattening }\end{array}$} \\
\hline & $\begin{array}{c}\text { Concentrado } \\
\text { Concentrate }\end{array}$ & $\begin{array}{c}\text { Feno } \\
\text { Hay }\end{array}$ & $\begin{array}{c}\text { Concentrado } \\
\text { Concentrate }\end{array}$ & $\begin{array}{r}\text { Feno } \\
\text { Hay }\end{array}$ \\
\hline$\overline{\mathrm{MS}(\%)}$ & 84,66 & 82,30 & 85,98 & 82,63 \\
\hline $\mathrm{MO}^{1}$ & 97,59 & 93,65 & 97,43 & 93,62 \\
\hline $\mathrm{PB}^{1}$ & 15,97 & 12,98 & 16,59 & 11,32 \\
\hline $\mathrm{EE}^{1}$ & 2,58 & 1,12 & 2,72 & 1,26 \\
\hline $\mathrm{FDN}^{1}$ & 13,37 & 77,64 & 13,50 & 77,86 \\
\hline $\mathrm{CNF}^{1}$ & 65,66 & 1,91 & 64,62 & 3,17 \\
\hline $\begin{array}{l}\mathrm{EM} \\
(\mathrm{Mcal} / \mathrm{k}\end{array}$ & 3,41 & 2,29 & 3,49 & 2,29 \\
\hline
\end{tabular}

$1 \%$ na MS (\% in dry matter).

R. Bras. Zootec., v.34, n.1, p.257-267, 2005 
Tabela 2 - Teores médios de matéria seca (MS), matéria orgânica $(\mathrm{MO})$, proteína bruta $(\mathrm{PB})$, extrato etéreo (EE), fibra em detergente neutro (FDN), carboidratos não-fibrosos (CNF), nutrientes digestíveis totais (NDT) e energia metabolizável (EM) das rações

Table 2 - Dry matter (DM), organic matter (OM), crude protein $(C P)$, ether extract $(E E)$, neutral detergent fiber (NDF), nonfiber carbohydrates (NFC), total digestible nutrients (TDN) and metabolizable energy contents of the diets

\begin{tabular}{lcc}
\hline & \multicolumn{2}{c}{$\begin{array}{c}\text { Fases } \\
\text { Phases }\end{array}$} \\
\cline { 2 - 3 } Itens & Recria & Engorda \\
Items & Frowing & 83,37 \\
\hline MS (\%) & 83,24 & 95,14 \\
MO $^{1}$ & 95,22 & 13,43 \\
PB $^{1}$ & 14,18 & 1,80 \\
EE $^{1}$ & 1,70 & 51,68 \\
FDN $^{1}$ & 51,52 & 28,22 \\
CNF $^{1}$ & 27,81 & 68,03 \\
NDT & 69,77 & 2,77 \\
EM (Mcal/kg MS) & 2,74 & \\
\hline
\end{tabular}

1 em \% na MS (in \% dry matter).

teriores análises de nitrogênio total e EE, conforme metodologia descrita por Silva \& Queiroz (2002). Dentro de cada tratamento foi sorteado um animal para representá-lo (número suficiente, pois as amostras de cabeça, membro anterior e posterior apresentam-se semelhantes em sua composição física e química), do qual foram retiradas amostras da cabeça, de um membro anterior e de outro posterior, para, logo após, proceder-se à separação física de músculo, gordura, ossos e couro. Adotou-se este procedimento porque esses membros apresentaram estrutura óssea e conformação muscular diferentes das frações restantes do corpo. As amostras de rúmen, retículo, omaso, abomaso, intestino delgado, intestino grosso, gordura interna, mesentério e aparas foram agrupadas de forma proporcional e constituíram uma amostra composta de vísceras. O mesmo procedimento foi feito para as amostras de fígado, coração, rins, pulmões, língua, baço e carne industrial.

As amostras do tecido muscular, adiposo e ósseo da seção da $9^{\mathrm{a}}$ a $11^{\mathrm{a}}$ costela e da cabeça, amostras de tendões e ossos dos pés, das vísceras, órgãos, rabo e couro foram secas em estufa a $105^{\circ} \mathrm{C}$, por 72 horas, para obtenção do teor de matéria seca gordurosa (MSG), conforme Kock \& Preston (1979). Essas amostras foram pré-desengorduradas com éter de petróleo, segundo a técnica descrita por Kock \& Preston (1979), moídas e acondicionadas em recipi- entes de vidro para posteriores análises de cinzas (CZ), nitrogênio total e extrato etéreo (EE), segundo metodologia descrita por Silva \& Queiroz (2002). O peso do corpo vazio (PCVZ) dos animais foi obtido pela soma dos pesos de carcaça, sangue, couro, pés, cauda, vísceras e órgãos. A relação obtida entre o PCVZ e o peso vivo (PV) dos animais-referência foi utilizada para estimar o PCVZ inicial dos animais remanescentes nos tratamentos. Para conversão do PCVZ em PV dentro do intervalo de pesos incluídos no estudo, foi utilizada a relação obtida entre PCVZ e PV. Foram pesadas as duas meias-carcaças, resfriadas em câmara fria a $-5^{\circ} \mathrm{C}$; da meia-carcaça esquerda foi retirada uma seção da 9 a a $11^{\mathrm{a}}$ costela, conforme metodologia de Hankins \& Howe (1946), para posteriores dissecação e predição das proporções de músculos, gordura e ossos da carcaça, por intermédio das seguintes equações:

$$
\begin{array}{ll}
\text { Músculo: } & Y=16,08+0,80 \mathrm{X} \\
\text { Gordura: } & \mathrm{Y}=3,54+0,80 \mathrm{X} \\
\text { Ossos: } & \mathrm{Y}=5,52+0,57 \mathrm{X}
\end{array}
$$

em que $\mathrm{X}$ é a porcentagem do componente tecidual na seção.

Os conteúdos corporais de gordura, proteína e água foram determinados em função das concentrações percentuais destes nos órgãos, nas vísceras, no couro, sangue, na cauda, cabeça, nos pés e constituintes separados (gordura, músculo e ossos) da seção da 9a a $11^{\text {a }}$ costela, sendo estes últimos representantes da composição física da carcaça.

A porcentagem de proteína da carcaça foi calculada pela multiplicação da composição física da carcaça (estimada pela seção da 9a a 11 1 a costela) pela composição química (proteína) de cada tecido constituinte da seção da $9 \underline{a}$ a $11 \underline{\text { a }}$ costela. O conteúdo de energia corporal foi obtido a partir dos conteúdos corporais de proteína e gordura e de seus equivalentes, conforme ARC (1980).

$$
\mathrm{C} \mathrm{E}(\text { Mcal })=5,6405 \mathrm{X}+9,3929 \mathrm{Y}
$$

em que $\mathrm{X}=$ proteína corporal $(\mathrm{kg}) ; \mathrm{Y}=$ gordura corporal $(\mathrm{kg})$; e $\mathrm{CE}=$ conteúdo de energia (Mcal).

Os conteúdos de gordura, proteína e energia retida no corpo vazio dos animais de cada grupo genético, em cada estádio de crescimento, foram 
estimados por equações de regressão do logaritmo do conteúdo corporal de proteína, gordura ou energia, em função do logaritmo do PCVZ, segundo o ARC (1980), conforme o seguinte modelo:

$$
\mathbf{Y}=\mathbf{a}+\mathbf{b X}+\mathbf{e}
$$

em que: $\mathrm{Y}=$ logaritmo do conteúdo total de proteína $(\mathrm{kg})$, gordura $(\mathrm{kg})$ ou energia (Mcal) retido no corpo vazio; $a=$ constante; $b=$ coeficiente de regressão do logaritmo do conteúdo de proteína, gordura, ou energia, em função do logaritmo do PCVZ; e = erro aleatório; e $\mathrm{X}=\log \mathrm{PCVZ}$.

As equações foram elaboradas adicionando-se os valores dos animais-referência.

Derivando-se as equações de predição do conteúdo corporal de proteína, gordura, ou energia, em função do logaritmo do PCVZ, foram obtidas as exigências líquidas de proteína e energia, para ganho de $1 \mathrm{~kg}$ de PCVZ a partir da seguinte equação:

$$
\mathbf{Y}=\mathbf{b} \cdot \mathbf{1 0}^{\mathrm{a}} \cdot \mathbf{X}^{\mathrm{b}-1}
$$

em que: $\mathrm{Y}=$ conteúdo de gordura no ganho, ou exigência líquida de proteína ou energia; $a$ e b = intercepto e coeficiente de regressão, respectivamente, das equações de predição dos conteúdos corporais de gordura, proteína ou energia; e X = PCVZ (kg).

Os resultados foram interpretados estatisticamente por meio de análises de variância e regressão, utilizando-se o Sistema de Análises Estatísticas e Genéticas - SAEG (UFV, 1995).

As exigências de energia líquida de mantença (ELm) foram estimadas pelo anti-log do intercepto da equação obtida pela regressão linear entre o logaritmo da produção de calor (PC) e o consumo de energia metabolizável (CEM).

As exigências de proteína metabolizável (PM) foram estimadas de acordo com a metodologia descrita no NRC (1996), pela soma da proteína metabolizável de mantença (PMm) e da exigência líquida de proteína para ganho (PLg), considerando-se o fator de eficiência de utilização de proteína para ganho de 0,492 para animais acima de $300 \mathrm{~kg}$ de PCVZ; para animais com PCVZ menor que $300 \mathrm{~kg}$, foi usada a seguinte equação: Eficiência de utilização de $\mathrm{PM}=(83,4-(0,114 \mathrm{x}$ PCVZ)), segundo Ainslie et al. (1993). Assim:

$$
\begin{gathered}
\mathrm{PMt}=3,8 . \mathrm{PV}^{0,75}+\mathrm{PLg} / 0,492 \geq 300 \mathrm{~kg} \text { de } \mathrm{PCVZ} \\
\mathrm{PMt}=3,8 . \mathrm{PV}^{0,75}+\mathrm{PLg} /(83,4-(0,114 \mathrm{x} \mathrm{PCVZ})) \\
<300 \mathrm{~kg} \text { de } \mathrm{PCVZ}
\end{gathered}
$$

em que PLg = determinada neste estudo.

\section{Resultados e Discussão}

O teste de homogeneidade de "b" das equações de estimativa da composição corporal não indicou diferenças entre os grupos Holandês x Gir e Holandês x Guzerá, portanto, os dados destes grupos foram agrupados e o conjunto denominado de mestiços leiteiros. As relações obtidas para estimativa do PCVZ, a partir do peso vivo dos animais, foram obtidas individualmente para mestiços leiteiros e zebu. As equações obtidas foram: PCVZ = PV * 0,865 (mestiços leiteiros) e $\mathrm{PCVZ}=\mathrm{PV} * 0,862$ (zebu). As relações $\mathrm{PCVZ/PV}$, neste trabalho, não apresentaram diferenças significativas entre as fases de recria e engorda.

O PCVZ estimado a partir das relações acima, para um animal de $400 \mathrm{~kg}$, foram de $346 \mathrm{~kg}$ e de $344,8 \mathrm{~kg}$ para mestiços e zebu, respectivamente. Esses valores foram inferiores em 2,9\% (mestiços) e 3,2\% (zebu) ao obtido (356,4 kg) pelo NRC (1996), por intermédio da equação $\mathrm{PCVZ}=\mathrm{PV} * 0,891$, para um animal de 400 $\mathrm{kg}$ de peso vivo. Véras et al. (2000), a partir da equação $\mathrm{PCVZ}=\mathrm{PV} * 0,884$, obtida em seu trabalho, obteve $353,6 \mathrm{~kg}$ de PCVZ para um animal de $400 \mathrm{~kg}$ de peso vivo, valor superior em 2,2 e 2,5\% aos obtidos para mestiços e zebu, respectivamente, neste trabalho.

A relação entre o GPCVZ e GPV para zebu e mestiços, em recria e engorda, foi de GPV $=0,94 \mathrm{x}$ GPCVZ, GPV $=1,00 \times$ GPCVZ, GPV $=1,00 \times$ GPCVZ e GPV = 0,96 x GPCVZ, respectivamente. Portanto, as exigências para ganho de $1 \mathrm{~kg}$ de PCVZ devem ser multiplicadas pelos fatores 0,$94 ; 1,00$ para zebu e mestiços em recria; e 1,00 e 0,96 para zebu e mestiço em engorda, respectivamente. Dessa maneira, obtêm-se as exigências para ganho de $1 \mathrm{~kg}$ de PV.

Na Tabela 3, são apresentados os parâmetros das equações de regressão do logaritmo do conteúdo corporal de gordura $(\mathrm{kg})$, energia (Mcal) e proteína $(\mathrm{kg})$ no corpo vazio, em função do logaritmo do peso corporal vazio (PCVZ), obtidas para animais mestiços leiteiros e zebu, em recria e engorda. Os coeficientes de determinação das equações variaram de 0,69 a 0,98 , mostrando bom ajustamento das equações aos dados.

As quantidades totais de proteína e gordura corporal dos animais mestiços leiteiros e zebu aumentaram com a elevação do peso corporal, tanto na recria quanto na engorda (Tabela 4); resultados que corroboram os obtidos por Freitas (1995), Ferreira et al. (1999) e Rocha \& Fontes (1999). 
Tabela 3 - Parâmetros das equações de regressão do logarítmo do conteúdo corporal de gordura (kg), proteína (kg) e energia (Mcal) no corpo vazio, em função do logaritmo do peso corporal vazio (PCVZ) para animais mestiços leiteiros e zebu, nas fases de recria e engorda

Table 3 - Parameters of the regression equations of the logarithm of the contents of fat $(\mathrm{kg})$, protein $(\mathrm{kg})$ and energy (Mcal) in the empty body, in function of the logarithm of the empty body weight (EBW) of dairy crossbreed and zebu animals, in the growing and fattening phases

\begin{tabular}{|c|c|c|c|c|}
\hline $\begin{array}{l}\text { Grupo racial } \\
\text { Racial groups }\end{array}$ & $\begin{array}{l}\text { Itens } \\
\text { Items }\end{array}$ & $\begin{array}{l}\text { Intercepto } \\
\text { Intercept }\end{array}$ & $\begin{array}{c}\text { Coeficiente } \\
\text { Coefficient }\end{array}$ & $\mathrm{R}^{2}$ \\
\hline & & $\begin{array}{c}\text { Recria } \\
\text { Growing }\end{array}$ & & \\
\hline Mestiços leiteiros & Gordura & $-3,992820$ & 2,295710 & 0,73 \\
\hline Dairy crossbreeds & Fat & & & \\
\hline Zebu & Gordura & $-3,258040$ & 2,022300 & 0,69 \\
\hline Zebu & Fat & & & \\
\hline Mestiços leiteiros & Proteína & $-0,592419$ & 0,942433 & 0,93 \\
\hline Dairy crossbreeds & Protein & & & \\
\hline Zebu & Proteína & $-0,558435$ & 0,931245 & 0,97 \\
\hline Zebu & Protein & & & \\
\hline Mestiços leiteiros & Energia & $-1,046760$ & 1,588500 & 0,87 \\
\hline Dairy crossbreeds & Energy & & & \\
\hline Zebu & Energia & $-0,976454$ & 1,580710 & 0,84 \\
\hline \multirow[t]{3}{*}{ Zebu } & Energy & & & \\
\hline & & Engorda & & \\
\hline & & Fattening & & \\
\hline Mestiços leiteiros & Gordura & $-4,126440$ & 2,352890 & 0,90 \\
\hline Dairy crossbreeds & Fat & & & \\
\hline Zebu & Gordura & $-3,170340$ & 1,975880 & 0,87 \\
\hline Zebu & Fat & & & \\
\hline Mestiços leiteiros & Proteína & $-0,475745$ & 0,890712 & 0,96 \\
\hline Dairy crossbreeds & Protein & & & \\
\hline Zebu & Proteína & $-0,390622$ & 0,857771 & 0,98 \\
\hline Zebu & Protein & & & \\
\hline Mestiços leiteiros & Energia & $-1,291360$ & 1,694900 & 0,96 \\
\hline Dairy crossbreeds & Energy & & & \\
\hline Zebu & Energia & $-0,879940$ & 1,534240 & 0,95 \\
\hline Zebu & Energy & & & \\
\hline
\end{tabular}

A partir da relação G/PB (gordura/proteína bruta), notam-se as mudanças na composição dos tecidos, que, geralmente, aumentam com o incremento do peso vivo. Porém, no presente trabalho, essa relação manteve-se semelhante, tanto na recria como na engorda. As equações de estimativas de exigências líquida de ganho, obtidas pela derivação das equações apresentadas na Tabela 3, constam na Tabela 5.

As exigências líquidas de proteína e energia, os conteúdos de gordura (kg de ganho de PCVZ) e a relação G/PB são apresentados na Tabela 6. Nota-se que os animais zebu apresentaram, numericamente, maior conteúdo de gordura por kg de ganho, na fase de recria, que os mestiços, indicando deposição precoce de gordura nos zebu, fato que contribuiu diretamente para o aumento numérico das exigências energéticas dos animais desse grupo racial, pois as exigências de energia são dependentes da proporção de gordura no ganho. Assim, infere-se que os zebu possuem maturidade fisiológica mais precoce que os mestiços. Lana et al. (1992), trabalhando com zebu e mestiços, também chegaram à conclusão de que os animais zebu apresentam maturidade fisiológica mais precoce que os mestiços.

$\mathrm{Na}$ fase de engorda, os animais mestiços apresentaram, em valores absolutos, maior conteúdo de gordura e, consequentemente, exigência de energia numericamente maior que os animais zebu, provavelmente porque os mestiços, nessa fase, tenderam a obter maior consumo de matéria seca $(8,66 \mathrm{~kg})$ que os zebu $(7,95 \mathrm{~kg}$ ) (Alves et al., 2004). Entretanto, Teixeira et al. (1987), Pires et al. (1993) e Lana et al. (1992) observaram que animais zebuínos possuem maior quantidade de gordura e energia corporal que mestiços, ao passo que Jorge et al. (1999), trabalhando com animais Gir, Guzerá e Nelore, apesar de não ter encontrado diferença entre os grupos, observaram tendência de maior teor de gordura corporal para os animais Guzerá. 
Tabela 4 - Conteúdos corporais totais (kg) de proteína (PBT) e gordura (GT) e conteúdos de energia (Mcal/kg), em função do peso de corpo vazio (PCVZ), e relação entre conteúdos de gordura e proteína (G/PB), para animais mestiços leiteiros e zebu, nas fases de recria e engorda

Table 4 - Body contents $(\mathrm{kg})$ of the protein $(C P)$ and fat $(F)$ and energy contents (Mcal/kg), in function of the empty body weight (EBW), and relation between fat and protein $(F / C P)$ contents, for dairy crossbreeds and zebu animals, in the growing and fattening phases

\begin{tabular}{|c|c|c|c|c|}
\hline $\begin{array}{l}\mathrm{PCVZ}(\mathrm{Kg}) \\
E B W\end{array}$ & $\begin{array}{l}\mathrm{PBT}(\mathrm{kg}) \\
\quad C P\end{array}$ & $\begin{array}{c}\mathrm{GT}(\mathrm{kg}) \\
F\end{array}$ & $\begin{array}{c}\text { Energia }(\mathrm{Mcal} / \mathrm{kg} \text { de } \mathrm{PCVZ}) \\
\text { Energy }(\text { Mcal/kg of EBW })\end{array}$ & $\begin{array}{l}\text { Relação }(\mathrm{G} / \mathrm{PB}) \\
\text { Relation }(F / C P)\end{array}$ \\
\hline \multicolumn{5}{|c|}{ Recria (Mestiço) ${ }^{1}$} \\
\hline 175 & 2,21 & 2,60 & 2,44 & 1,18 \\
\hline 200 & 2,27 & 2,66 & 2,50 & 1,17 \\
\hline 225 & 2,32 & 2,71 & 2,55 & 1,17 \\
\hline 250 & 2,37 & 2,76 & 2,60 & 1,16 \\
\hline 275 & 2,41 & 2,80 & 2,64 & 1,16 \\
\hline \multicolumn{5}{|c|}{ Recria $(Z e b u)^{2}$} \\
\hline 175 & 2,21 & 2,54 & 2,44 & 1,15 \\
\hline 200 & 2,27 & 2,60 & 2,50 & 1,14 \\
\hline 225 & 2,32 & 2,65 & 2,55 & 1,14 \\
\hline 250 & 2,37 & 2,70 & 2,60 & 1,14 \\
\hline 275 & 2,41 & 2,74 & 2,64 & 1,14 \\
\hline \multirow{2}{*}{\multicolumn{5}{|c|}{$\begin{array}{c}\text { Engorda (Mestiço) }{ }^{1} \\
\text { Fattening (Dairy crossbreeds) }\end{array}$}} \\
\hline & & & & \\
\hline 300 & 2,43 & 2,85 & 2,70 & 1,17 \\
\hline 350 & 2,49 & 2,91 & 2,77 & 1,17 \\
\hline 400 & 2,55 & 2,97 & 2,83 & 1,16 \\
\hline 450 & 2,60 & 3,02 & 2,88 & 1,16 \\
\hline 500 & 2,65 & 3,07 & 2,93 & 1,16 \\
\hline \multirow{2}{*}{\multicolumn{5}{|c|}{${\text { Engorda }(\mathrm{Zebu})^{2}}^{2}$}} \\
\hline & & & & \\
\hline 300 & 2,41 & 2,77 & 2,66 & 1,15 \\
\hline 350 & 2,48 & 2,84 & 2,73 & 1,14 \\
\hline 400 & 2,53 & 2,90 & 2,79 & 1,14 \\
\hline 450 & 2,59 & 2,95 & 2,84 & 1,14 \\
\hline 500 & 2,63 & 2,99 & 2,88 & 1,14 \\
\hline
\end{tabular}

${ }^{1}$ Mestiços PCVZ $=\mathrm{PV}{ }^{*} 0,865 ;{ }^{2}$ Zebu PCVZ $=\mathrm{PV}{ }^{*} 0,862$ (Dairy crossbreeds $E B W=L W{ }^{*} .865 ; Z e b u E B W=L W^{*} .862$ ).

Tabela 5 - Equações de estimativas de exigências líquida de ganho para animais mestiços leiteiros e zebu, nas fases de recria e engorda

Table 5 - Equations of the estimate of the net requirements of gain of dairy crossbreeds and zebu animals, in the growing and fattening phases

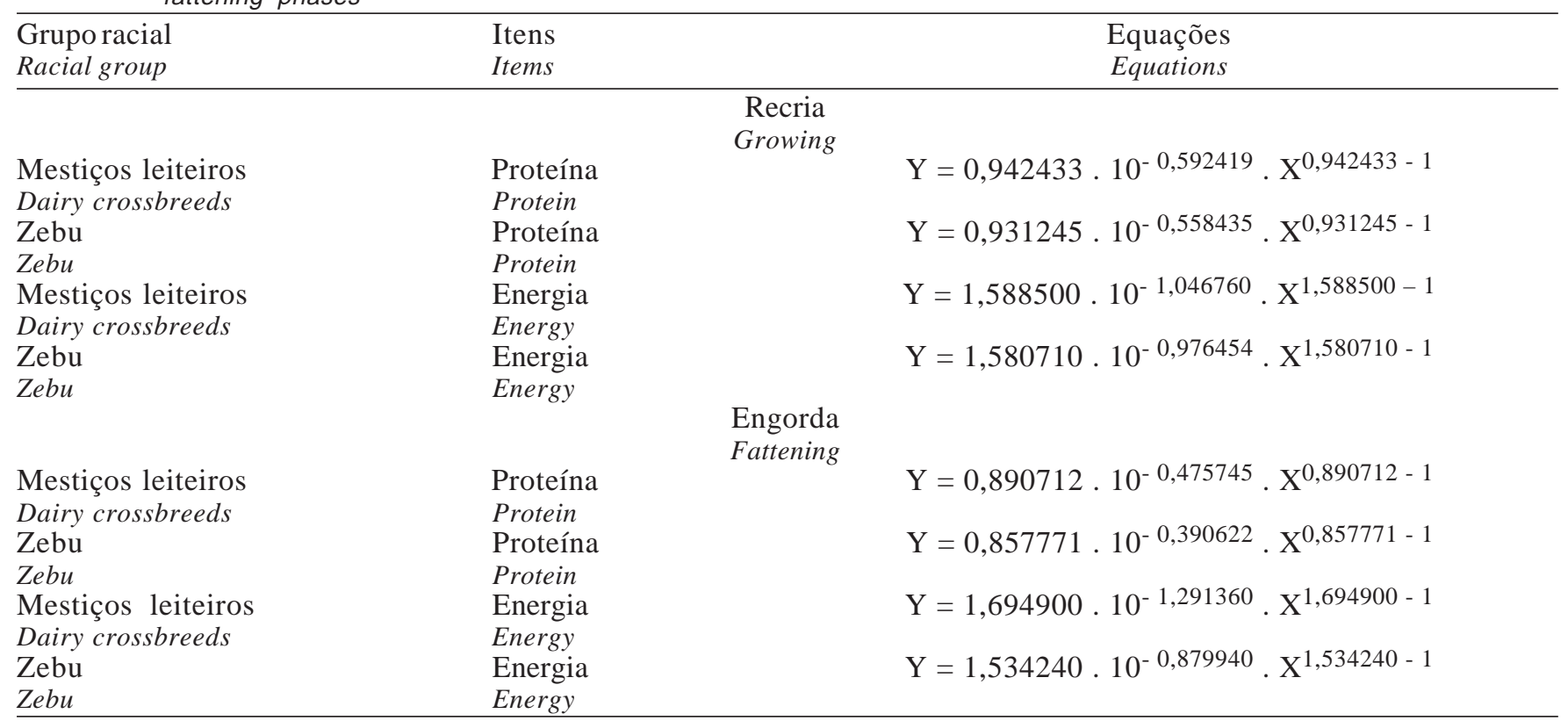

R. Bras. Zootec., v.34, n.1, p.257-267, 2005 
Tabela 6 - Exigências líquidas de proteína (g) e de energia (Mcal) por kg de ganho de peso do corpo vazio (PCVZ) e relação gordura/proteína (G/PB) no ganho de animais mestiços leiteiros e zebu, nas fases de recria e engorda Table 6 - Net requirements of protein ( $g$ ) and energy (Mcal) by $\mathrm{kg}$ of empty body weight gain (EBWG) and fat/protein (F/CP) relation in gain of the dairy crossbreeds and zebu animals, in growing and fattening phases

\begin{tabular}{lccc}
\hline $\mathrm{PV}(\mathrm{Kg})$ & Proteína $(\mathrm{g} / \mathrm{kg} \mathrm{GPCVZ})$ & Energia $(\mathrm{Mcal} / \mathrm{kg} \mathrm{GPCVZ})$ & Relação $(\mathrm{G} / \mathrm{PB})$ \\
$L W$ & Protein $(\mathrm{g} / \mathrm{kg} E B W G)$ & Energy $($ Mcal/kg EBWG) & Relation $(F / C P)$ \\
\hline
\end{tabular}

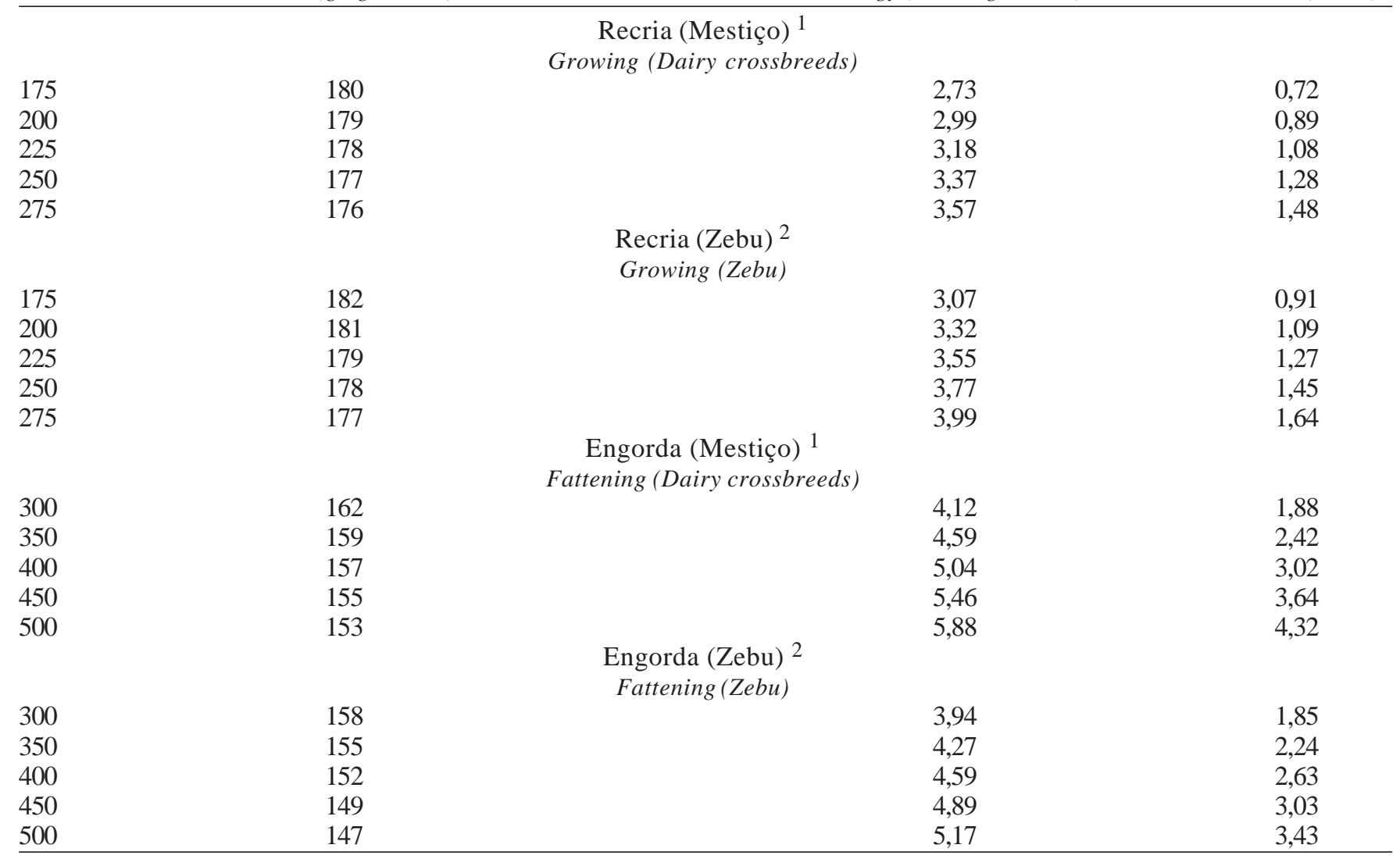

${ }^{1}$ Mestiços PCVZ $=\mathrm{PV} * 0,865 ;{ }^{2}$ Zebu PCVZ $=\mathrm{PV} *{ }^{*} 0,862$ (Dairy crossbreeds $E B W=L W * .865 ; Z$ ebu $\left.E B W=L W{ }^{*} .862\right)$.

Com relação às exigências de proteína, os animais zebu e mestiços possuem exigências protéicas numericamente superiores na fase de recria, confirmando o fato de que, à medida que se eleva o peso corporal, as exigências de proteína decrescem, em decorrência da queda no desenvolvimento muscular. Estes resultados concordam com vários relatos encontrados na literatura (Peron et al., 1993; Fontes, 1995; Paulino et al., 1999; Véras et al., 2000; Silva et al., 2002).

Comparando-se as exigências protéicas entre mestiço e zebu, os resultados obtidos nesta pesquisa são semelhantes, tanto na fase de recria quanto na engorda, corroborando os resultados encontrados por Lana et al. (1992), que realizaram comparações entre nelore e mestiços acima de $350 \mathrm{~kg}$ de PV. As estimativas de proteína metabolizável para suprir as exigências foram obtidas adotando-se a metodologia descrita pelo NRC (1996) (Tabela 7).
As exigências de proteína metabolizável totais foram semelhantes entre mestiços e zebu. Paulino et al. (1999), trabalhando com animais zebu, obtiveram valores de proteína metabolizável total inferiores aos encontrados neste trabalho, para animais de 300 a $500 \mathrm{~kg}$ de PV. Verifica-se que as exigências de proteína metabolizável para mantença aumentam com a elevação do peso vivo, o que era esperado, pois, segundo Véras et al. (2000), as exigências protéicas para mantença são função do PV.

A partir da regressão do logaritmo da produção de calor (PC), em função do consumo de energia metabolizável (CEM), em kcal/PCVZ $0,75 /$ dia, foram obtidas as equações $\log \mathrm{PC}=1,88642+0,0015 \mathrm{CEM}$, $\mathrm{r}^{2}=0,95$ e $\mathrm{PC}=1,8998+0,0014 \mathrm{CEM}, \mathrm{r}^{2}=0,97$ para animais mestiços e zebu, respectivamente. Ao calcular-se o antilog dos interceptos, obtiveram-se valores de 76,99 e 79,40 kcal/PCVZ ${ }^{0,75} /$ dia como exigências de energia líquida de mantença (ELm) para animais 
Tabela 7 - Exigências líquidas de proteína para ganho (PLg), proteína metabolizável para ganho de $1 \mathrm{~kg}$ de peso vivo (PMg) e mantença (PMm) e proteína metabolizável total (PMt), em função do peso vivo (PV) para animais mestiços leiteiros e zebu, nas fases de recria e engorda

Table 7 - Net requirements of protein for gain $\left(N P_{g}\right)$, metabolizable protein for gain of $1 \mathrm{~kg}$ of live weight $\left(M P_{g}\right)$ and maintenance $\left(M P_{m}\right)$ and total metabolizable protein $\left(M P_{t}\right)$, in function of live weight (LW) for dairy crossbreeds and zebu animals, in the growing and fattening phases

\begin{tabular}{|c|c|c|c|c|}
\hline $\begin{array}{l}\mathrm{PV}(\mathrm{Kg}) \\
L W\end{array}$ & $\begin{array}{c}\operatorname{PLg}(\mathrm{g}) \\
N P_{g} \\
\end{array}$ & $\begin{array}{c}\operatorname{PMg}(\mathrm{g}) \\
M P_{g}\end{array}$ & $\begin{array}{c}\mathrm{PMm}(\mathrm{g}) \\
M P_{m}\end{array}$ & $\begin{array}{c}\mathrm{PMt}(\mathrm{g}) \\
M P_{t} \\
\end{array}$ \\
\hline \multicolumn{5}{|c|}{ Recria (Mestiço) ${ }^{1}$} \\
\hline \multicolumn{5}{|c|}{ Growing (Dairy crossbreeds) } \\
\hline 175 & 180 & 247 & 183 & 430 \\
\hline 200 & 179 & 254 & 202 & 456 \\
\hline 225 & 178 & 263 & 221 & 484 \\
\hline 250 & 177 & 273 & 239 & 512 \\
\hline 275 & 176 & 284 & 257 & 541 \\
\hline \multicolumn{5}{|c|}{ Recria (Zebu) ${ }^{2}$} \\
\hline \multicolumn{5}{|c|}{ Growing (Zebu) } \\
\hline 175 & 194 & 258 & 183 & 441 \\
\hline 200 & 192 & 265 & 202 & 467 \\
\hline 225 & 190 & 274 & 221 & 495 \\
\hline 250 & 189 & 282 & 239 & 521 \\
\hline 275 & 188 & 294 & 257 & 551 \\
\hline \multicolumn{5}{|c|}{ Engorda (Mestiço) ${ }^{1}$} \\
\hline \multicolumn{5}{|c|}{ Fattening (Dairy crossbreeds) } \\
\hline 300 & 169 & 281 & 274 & 555 \\
\hline 350 & 166 & 306 & 307 & 613 \\
\hline 400 & 163 & 303 & 340 & 643 \\
\hline 450 & 161 & 299 & 371 & 670 \\
\hline 500 & 159 & 295 & 402 & 697 \\
\hline \multicolumn{5}{|c|}{ Engorda $(\mathrm{Zebu})^{2}$} \\
\hline \multicolumn{5}{|c|}{ Fattening (Zebu) } \\
\hline 300 & 158 & 267 & 274 & 541 \\
\hline 350 & 155 & 290 & 307 & 597 \\
\hline 400 & 152 & 284 & 340 & 624 \\
\hline 450 & 149 & 278 & 371 & 649 \\
\hline 500 & 147 & 274 & 402 & 676 \\
\hline
\end{tabular}

1. Mestiços PCVZ = PV * 0,865; ${ }^{2}$ - Zebu PCVZ $=P V * 0,862$ (Dairy crossbreeds $E B W=L W * 0,865$; Zebu $E B W=L W * 0,862$ )

mestiços e zebu, respectivamente. Os valores obtidos nesta pesquisa para mestiço e zebu foram maiores que o relatado por Paulino et al. (1999), de 60,38 kcal/ $\mathrm{PCVZ}^{0,75} /$ dia para exigência de ELm para zebuínos, mas foram inferiores aos encontrados por Véras et al. (2000) e Silva et al. (2002), de 82,79 e 83,70 kcal/ $\mathrm{PCVZ}^{0,75} / \mathrm{dia}$, respectivamente; os últimos autores trabalharam com animais inteiros, o que pode ter influenciado os resultados. Segundo o NRC (1996), a exigência de ELm é $15 \%$ maior em animais inteiros. Os valores verificados nesta pesquisa estão dentro da faixa (70 a $\left.80 \mathrm{kcal} / \mathrm{PCVZ}^{0,75} / \mathrm{dia}\right)$ encontrada por Boin (1995), para bovinos zebuínos. O valor de ELm obtido para mestiços $\left(76,99 \mathrm{kcal} / \mathrm{PCVZ}^{0,75} / \mathrm{dia}\right)$ é semelhante ao encontrado pelo NRC (1996), de $77 \mathrm{kcal} / \mathrm{PCVZ}^{0,75} /$ dia.

O local de deposição das reservas de gordura é um fator que possui substancial impacto sobre as exigências de energia de mantença de bovinos. Segundo Véras et al. (2000), em raças com aptidão leiteira, os maiores depósitos de gordura encontram-se nos componentes não-carcaça, enquanto nas raças de corte os depósitos periféricos são mais pronunciados. Ao comparar as exigências líquidas de energia para mantença, para animais com peso vivo de 200 a $500 \mathrm{~kg}$ (Tabela 8), e as exigências de ELm obtidas por Silva et al. (2002), verifica-se grande semelhança entre os valores. Todavia, os valores encontrados por

Tabela 8 - Exigências líquidas de energia para mantença, em Mcal/animal/dia, em função do peso vivo (PV) para animais mestiços leiteiros e zebu, nas fases de recria e engorda

Table 8 - Net requeriments of energy for maintenance, in Mcal/animal/day, in function of live weight ( $L W)$ for dairy crossbreeds and zebu animals, in the growing and fattening phases

\begin{tabular}{|c|c|}
\hline $\begin{array}{l}\mathrm{PV}(\mathrm{kg}) \\
L W\end{array}$ & $\begin{array}{l}\text { ELm (Mcal/animal/dia) } \\
N E_{m}(\text { Mcal/animal/day })\end{array}$ \\
\hline & Recria (Mestiço) ${ }^{1}$ \\
\hline & Growing (Dairy crossbreeds) \\
\hline 175 & 3,70 \\
\hline 200 & 4,09 \\
\hline 225 & 4,47 \\
\hline 250 & 4,84 \\
\hline \multirow[t]{3}{*}{275} & 5,20 \\
\hline & $\operatorname{Recria}(\mathrm{Zebu})^{2}$ \\
\hline & Growing (Zebu) \\
\hline 175 & 3,82 \\
\hline 200 & 4,22 \\
\hline 225 & 4,61 \\
\hline 250 & 4,92 \\
\hline \multirow[t]{3}{*}{275} & 5,36 \\
\hline & Engorda (Mestiço) ${ }^{1}$ \\
\hline & Fattening (Dairy crossbreeds) \\
\hline 300 & 5,55 \\
\hline 350 & 6,23 \\
\hline 400 & 6,89 \\
\hline 450 & 7,52 \\
\hline \multirow[t]{3}{*}{500} & 8,14 \\
\hline & Engorda (Zebu) ${ }^{2}$ \\
\hline & Fattening (Zebu) \\
\hline 300 & 5,72 \\
\hline 350 & 6,42 \\
\hline 400 & 7,10 \\
\hline 450 & 7,76 \\
\hline 500 & 8,39 \\
\hline
\end{tabular}

${ }^{1}$ Mestiços PCVZ $=\mathrm{PV}{ }^{*} 0,865 ;{ }^{2}$ Zebu PCVZ $=\mathrm{PV} *{ }^{*} 0,862$ (Dairy crossbreeds $E B W=L W^{*}$.865; Zebu $\left.E B W=L W^{*} .862\right)$. 
Paulino et al. (1999), com zebuínos, e por Veloso et al. (2002), com Nelore x Limousin, foram inferiores aos encontrados neste trabalho.

\section{Conclusões}

As exigências energéticas para mantença são de 76,99 e 79,40 kcal/PCVZ ${ }^{0,75} /$ dia, para mestiço e zebu, respectivamente.

As exigências líquidas de proteína e de proteína metabolizável para ganho apresentam-se semelhantes entre mestiço e zebu, em ambas as fases.

\section{Literatura Citada}

AGRICULTURAL AND FOOD RESEARCH COUNCIL AFRC. Energy and protein requirement of ruminantes. Wallingford: Commonwealth Agricultural Bureaux International, 1993. 159p.

AGRICULTURAL RESEARCH COUNCIL - ARC. The nutrient requirements of ruminant livestock. London: Commonwealth Africultural Bureaux, 1980. 351p.

AGRICULTURAL RESEARCH COUNCIL - ARC. The nutrient requirements of ruminant livestock. Report of the protein group of the Agricultural Research Council Working Party on the nutrient requirements of ruminants. s.e., (Supplement, 1), 1984. 45p.

AINSLIE, S.J.; FOX, D.G.; PERRY, T.C. et al. Predicting amino acid adequacy of diets fed to Holstein steers. Journal of Animal Science, v.71, p.1312-1319, 1993.

ALVES, D.D.; PAULINO, M.F.; BACKES, A.A. Características de carcaças de bovinos zebu e cruzados holandês-zebu (F1), nas fases de recria e terminação. Revista Brasileira de Zootecnia, v.33, n.5, p.1274-1284, 2004.

BACKES, A.A.; BONNECARRÈRE SANCHEZ, L.M.; GONÇALVES, M.B.F. et al. Composição corporal e exigências líquidas de energia e proteína para ganho de peso de novilhos santa gertrudis. Revista Brasileira de Zootecnia, v.31, n.6, p.2307-2313, 2002.

BOIN, C. Alguns dados sobre exigências de energia e de proteína de zebuínos. In: SIMPÓSIO INTERNACIONAL SOBRE EXIGÊNCIAS NUTRICIONAIS DE RUMINANTES, 1995, Viçosa, MG. Anais...Viçosa, MG: Universidade Federal de Viçosa, 1995. p.457-466.

FERREIRA, M.A.; VALADARES FILHO, S.C.; SILVA, J.F.C. et al. Composição corporal e exigências líquidas de proteína e energia para ganho de peso de bovinos $\mathrm{F}_{1}$ Simental $\mathrm{x}$ Nelore. Revista Brasileira de Zootecnia, v.28, n.2, p.352-360, 1999.

FERRELL, C.L.; JENKINS, T.G. Cow type and the nutritional environment: nutritional aspects. Journal of Animal Science, v.61, n.3, p.725-741, 1985.

FONTES, C.A .A. Composição corporal, exigências líquidas de nutrientes para ganho de peso e desempenho produtivo de animais zebuínos e mestiços europeu - zebu. Resultados experimentais. In: SIMPÓSIO INTERNACIONAL SOBRE EXIGÊNCIAS NUTRICIONAIS DE RUMINANTES, 1995, Viçosa, MG. Anais... Viçosa, MG: Universidade Federal de Viçosa, 1995. p.419-455.
FREITAS, J.A. Composição corporal e exigências de energia e proteína de bovinos (zebuínos e mestiços) e bubalinos não-castrados, em confinamento. Viçosa, MG: Universidade Federal de Viçosa, 1995. 75p. Dissertação (Mestrado em Zootecnia) - Universidade Federal de Viçosa, 1995.

HANKINS, O.G.; HOWE, P.E. Estimation of the composition of beef carcasses and cuts. Washington, D.C.: 1946. (Technical Bulletin - USA, 926).

INSTITUT NATIONAL DE LA RECHERCHE AGRONOMIQUE - INRA. Alimentation des bovines, ovins, et caprins. Paris: INRA, 1988. 147p.

JORGE, A.M.; FONTES, C.A.A.; PAULINO, M.F. Composição corporal de bovinos de quatro raças zebuínas, abatidos em diferentes estádios de maturidade. Revista Brasileira de Zootecnia, v.28, n.2, p.388-394, 1999.

KOCK, S.W.; PRESTON, R.L. Estimation of bovine carcass composition by the urea dilution technique. Journal of Animal Science, v.48, n.2, p.319-327, 1979.

LANA, R.P.; FONTES, C.A.A.; PERON, A.J. et al. Composição corporal e do ganho de peso e exigências de energia, proteína e macroelementos minerais (Ca, P, Mg, Na e K), de novilhos de cinco grupos raciais. 1. Conteúdo corporal e do ganho de peso em gordura, proteína e energia. Revista Brasileira de Zootecnia, v.21, n.3, p.518-527, 1992.

LOFGREEN, G.P.; GARRETT, W.N. A system for expressing net energy requirements and feed values for growing and finishing beef cattle. Journal of Animal Science, v.27, n.3, p.793-806, 1968.

NATIONAL RESEARCH COUNCIL - NRC. Necessidades nutritivas del ganado vacuno. 3.ed. Buenos Aires: Hemisfério sur., 1984. 104p.

NATIONAL RESEARCH COUNCIL - NRC. Nutrient requirements of beef cattle. 7.ed. Washington, D.C.: 1996. $243 p$.

NATIONAL RESEARCH COUNCIL - NRC. Nutrient requirements of dairy cattle. 6.ed. Washington, D.C.: 1989. $158 \mathrm{p}$.

PAULINO, M.F.; FONTES, C.A.A.; GALVÃO, J.G. et al. Composição corporal e exigências de energia e proteína para ganho de peso de bovinos de quatro raças zebuínas. Revista Brasileira de Zootecnia, v.28, n.3, p.627-633, 1999.

PERON, A.J.; FONTES, C.A.A.; LANA, R.P. et al. Rendimento de carcaça e de seus cortes básicos e área corporal de bovinos de cinco grupos genéticos, submetidos a alimentação restrita e ad libitum. Revista Brasileira de Zootecnia, v.22, n.2, p.238-247, 1993.

PIRES, C.C.; FONTES, C.A.A.; GALVÃO, J.G. et al. Exigências nutricionais de bovinos de corte em acabamento. II. Exigências de energia para mantença e ganho de peso. Revista Brasileira de Zootecnia, v.22, n.1, p.121-132, 1993.

ROCHA, E.O.; FONTES, C.A.A. Composição corporal, composição do ganho de peso e exigências nutricionais de novilhos de origem leiteira. Revista Brasileira de Zootecnia, v.28, n.1, p.159-168, 1999.

SILVA, D.J.; QUEIROZ, A.C. Análise de alimentos (métodos químicos e biológicos). Viçosa, MG: Universidade Federal de Viçosa, 2002. p.235.

SILVA, F.F.; VALADARES FILHO, S.C.; ÍTAVO, L.C.V. et al. Composição corporal e requisitos energéticos e protéicos de bovinos Nelore, não-castrados, alimentados com rações contendo diferentes níveis de concentrado e proteína. Revista Brasileira de Zootecnia, v.31, n. 1, suppl. p.503-513, 2002. 
TEIXEIRA, J.C.; COELHO DA SILVA, J.F.; GARCIA, J.A. Exigências de energia e proteína, composição e área corporal e principais cortes da carcaça em seis grupos genéticos de bovídeos. II. Exigências de energia e proteína. Revista Brasileira de Zootecnia, v.16, n.2, p.182-192, 1987.

UNIVERSIDADE FEDERAL DE VIÇOSA - UFV. SAEG Sistema de análises estatísticas e genética. Viçosa, MG. (Apostila), 1995.

VELOSO, C.M.; VALADARES FILHO, S.C.; GESUALDI JR., A. et al. Composição corporal e exigências energéticas e protéicas de bovinos $\mathrm{F}_{1}$ Limousin x Nelore, não-castrados, alimentados com rações contendo diferentes níveis de concentrado. Revista Brasileira de Zootecnia, v.31, n.3, p.1273-1285, 2002.
VÉRAS, A.S.C.; VALADARES FILHO, S.C.; COELHO DA SILVA, J.F. et al. Composição corporal e requisitos energéticos e protéicos de bovinos Nelore, não-castrados, alimentados com rações contendo diferentes níveis de concentrado. Revista Brasileira de Zootecnia, v.29, p.2379-2389, 2000 (supl. 2).

Recebido em: 09/05/03

Aceito em: 17/11/04 